\title{
Enhanced intestinal permeability in preterm babies with bloody stools
}

\author{
L T WEAVER, M F LAKER, AND R NELSON \\ Departments of Child Health and Clinical Biochemistry, Royal Victoria Infirmary, Newcastle upon Tyne
}

SUMMARY During a study of the intestinal permeability of newborn babies, three exhibited a sudden increase in lactulose absorption in association with the passage of bloody stools. An enhanced intestinal permeability may be an expression of the disruption of mucosal integrity in necrotising enterocolitis.

It has been suggested that increased intestinal permeability caused by mucosal injury may be the final common pathway in necrotising enterocolitis. ${ }^{1}$

\section{Patients, methods, and results}

The passive intestinal permeability of 38 preterm babies to lactulose and mannitol was studied longitudinally for 21 days after birth. ${ }^{2}$ These hydrophilic markers cross the gut wall passively, are not metabolised, and are fully recoverable in the urine. Both are handled in the same way by the body in all respects except routes of absorption. ${ }^{3}$ Lactulose, the larger molecule, is probably absorbed by a paracellular pathway via intercellular spaces between mucosal cells, at extrusion zones at villous tips and other sites of enterocyte loss. Mannitol, the smaller molecule, is thought to pass through aqueous pores in the enterocyte cell membrane. Less than $1 \%$ of ingested lactulose, and $5 \%$ of mannitol is absorbed by the healthy neonate.

Babies received regular milk feeds containing 200 $\mathrm{mg}$ lactulose and $40 \mathrm{mg}$ mannitol/100 $\mathrm{ml}(5 \cdot 8$ and $2 \cdot 2$ $\mathrm{mmol} / \mathrm{l}$ respectively) made up feed, amounts within those already present in many 'ready to feed' formulas. ${ }^{4}$ When a steady state of input and output had been reached, daily urine samples were collected for marker and creatinine analyses. The ratio of the amounts of the two markers in the urine to the fixed amounts in the feeds is an expression of the permeability of the gut to the markers.

The stippled area in the Figure represents the range of urinary lactulose:mannitol excretion ratios exhibited by normal babies. A decline in excretion ratios during the first week after starting oral feeds occurred. A parallel decline in lactulose:creatinine ratios indicated that this was due to a decrease in lactulose rather than an increase in mannitol absorption.

Three babies (represented by continuous lines in the Figure) showed a sudden increase in lactulose absorption in association with the passage of bloody stools. A baby of 34 weeks' gestation passed stools flecked with fresh blood on the fourth and fifth days after starting feeds, but otherwise remained clinically, biochemically, and haematologically well. No pathogens or enterotoxins were identified from her faeces or elsewhere. Proctoscopy showed an inflamed rectal mucosa. ${ }^{5}$ An 8 fold rise in the urinary latulose:mannitol excretion ratio was observed, representing an increase in lactulose absorption when expressed as a lactulose:creatinine ratio. The second baby, also of 34 weeks' gestation, passed four consecutive bloody stools four days after starting feeds, followed by a 3.5 fold rise in lactulose absorption, which returned to normal, however, within 24 hours. No cause for his symptoms was found. The third baby, of 31 weeks' gestation, showed an enhanced intestinal permeability to lactulose for four days before passing bloody stools. These were accompanied by abdominal distension but no stool pathogens or toxins were detected. Stopping milk feeds and the administration of clear fluids orally or intravenously led to full recovery in all babies.

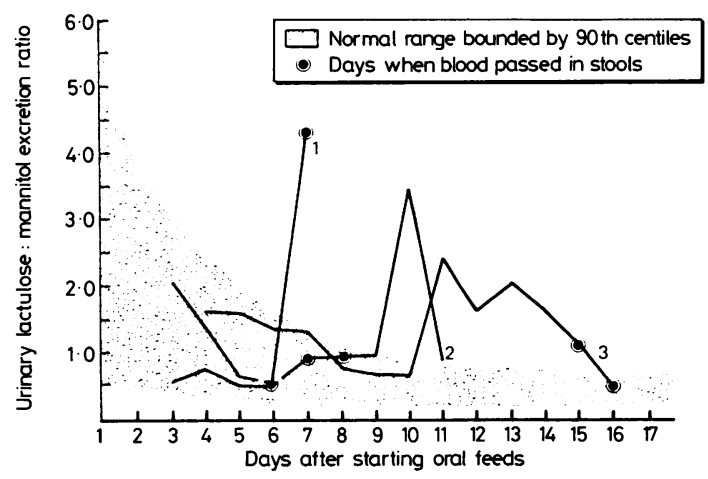

Figure Enhanced permeability ratios in three preterm babies who passed blood in their stools.

Conversion: traditional units to $S I$-lactulose $1 \mathrm{mg} / \mathrm{l} \approx 2.92 \mathrm{mmol} / \mathrm{l}$; mannitol $1 \mathrm{mg} / \mathrm{l} \approx 5.49 \mathrm{mmol} / \mathrm{l}$. 


\section{Discussion}

The enhanced urinary lactulose:mannitol excretion ratios observed in these three babies indicate a sudden increase in intestinal permeability to the larger marker, as has been described in children with active Crohn's disease. ${ }^{6}$ Enterocyte damage or loss may allow an abrupt and appreciable rise in lactulose uptake by increasing available paracellular pathways. Such a change is not reflected by an increased mannitol absorption, because the aqueous pore population by which only this smaller marker can pass is very large compared with the paracellular pathways available to both molecules.

Although hyperosmolar feeds have been incriminated in the pathogenesis of necrotising enterocolitis, ${ }^{1}$ we think it highly unlikely that the markers were responsible for our findings, as the concentrations used were well within those present in many infant milk formulas. ${ }^{4}$ We suggest that although it is not known whether the passage of bloody stools in our babies represented incipient enterocolitis, the enhanced intestinal permeability described might well allow the absorption of other molecules, such as microbial antigens and toxins, contributing to the devastating damage that characterises necrotising enterocolitis.

We are grateful to the staff of the Princess Mary Maternity Hospital for their help with this study which was supported by the Newcastle Health Authority.

\section{References}

1 Lake AM, Walker WA. Neonatal necrotizing enterocolitis; a disease of altered host defense. Clin Gastroenterol 1977;6: 463-80.

${ }^{2}$ Weaver LT, Laker MF, Neslon R. Intestinal permeability in the newborn. Arch Dis Child 1984;59:236-41.

3 Laker MF, Bull HJ, Menzies IS. Evaluation of mannitol for use as a probe marker of gastrointestinal permeability in man. Eur J Clin Invest 1982;12:485-91.

${ }^{4}$ Beach RC, Menzies IS. Lactulose and other non-absorbable sugars in infant milk feeds (letter). Lancet 1983;i:425-6.

${ }^{5}$ Fenton TR, Walker-Smith JA, Harvey DR. Proctoscopy in infancy with reference to its use in necrotising enterocolitis. Arch Dis Child 1981;56:121-4.

6 Pearson ADJ, Eastham EJ, Laker MF, Craft AW, Nelson R. Intestinal permeability in children with Crohn's disease and coeliac disease. $\mathrm{Br}$ Med J 1982;285:20-1.

Correspondence to Dr L T Weaver, The Children's Clinic, Royal Victoria Infirmary, Newcastle upon Tyne NE1 4LP.

Received 22 November 1983

\title{
Idiopathic apnoea of prematurity treated with doxapram and aminophylline
}

\author{
E SAGI, F EYAL, G ALPAN, D PATZ, AND I ARAD \\ Department of Paediatrics, Hadassah University Hospital, Jerusalem, Israel
}

SUMmaRY Doxapram infusion was given to five preterm infants in whom therapeutic concentrations of theophylline had failed to control episodes of apnoea. Doxapram successfully controlled the apnoea, the arterial blood $\mathrm{PCO}_{2}$ value decreased significantly, and no side effects were reported.

Apnoea of prematurity is a disorder frequently encountered in preterm neonates, and the hypoxia attributed to these attacks may threaten the integrity of the central nervous system. Since the introduction of aminophylline for the treatment of idiopathic apnoea of prematurity, the use of xanthines in various forms as respiratory stimulants has gained widespread acceptance. A considerable number of preterm infants with apnoea fail to respond satisfactorily, however, and require further measures such as continuous positive airways pressure or mechanical ventilation.

Doxapram, an analeptic agent with wide safety margins, is an effective respiratory stimulant in adults ${ }^{1}$ and has already been used to stimulate breathing immediately after birth ${ }^{2}$ or to overcome idiopathic apnoea of prematurity. ${ }^{3}$ We describe the response to doxapram infusion in five preterm infants in whom episodes of apnoea persisted despite adequate treatment with aminophylline.

\section{Patients and methods}

Preterm infants in this hospital are routinely connected to heart and respiratory rate monitors. Apnoea is defined as cessation of breathing associated with cyanosis or with bradycardia (a fall of 40 bpm from basal heart rate). Idiopathic apnoea of immaturity is diagnosed by exclusion of treatable 